$\mathrm{O}$ artigo expõe visões sobre a infância entre os Tempos Modernos e os Tempos Contemporâneos. Entre Rousseau e Nabokov, o autor prefere a posição historicista-romântica de Rorty como uma boa escolha para pensar os problemas da infância atualmente. $O$ artigo é escrito a partir da filosofia da educação.

Pragmatismo; Rousseau; Rorty; criança; filosofia da educação

\section{THE INFANCY IN} GEPETO'S CITY OR POSSIBILITIES OF NEOPRAGMATISM TO THINK CHILDREN RIGTHS IN POST-MODERN CULTURE

The paper explains points of view about the childbood between Modern Age and Contemporary Age. Between Rousseau and Nabokov, the autbor prefers Richard Rorty's romantic-bistoricist position as a good cboice to think the troubles of the childbood nowadays. The paper is writen from philosopby of education.

Pragmatism; Rousseau; Rorty; child; philosopby of education

\section{A INFÂNCIA \\ NA CIDADE \\ DE GEPETO OU \\ POSSIBILIDADES \\ DO}

NEOPRAGMATISMO

PARA PENSARMOS

OS DIREITOS

DA CRIANÇA

NA CULTURA

PÓS-MODERNA $^{1}$

Paulo Ghiraldelli Jr.

$\mathbb{N}$

o início de 1996, por ocasião da anulação de uma sentença de condenação de um encanador, acusado de estuprar uma menina de 12 anos, o juiz do Supremo Tribunal Federal Marco Aurélio de Mello fez o seguinte comentário: "Nos nossos dias, não há crianças, mas mo-

Professor de Filosofia da Educação e Filosofia Contemporânea na Unesp, campus de Marília. 
ças de 12 anos". A frase foi parar no Fantástico, da Rede Globo, que chegou a submetê-la a uma enquete nacional, na qual uma boa parte da população brasileira manifestou seu acordo com o juiz. Por outro lado, a imprensa liberal, como a Folha de S.Paulo, por intermédio de articulistas e jornalistas, repudiou a frase. No final de julho daquele ano, em debate promovido pela Folha, a então deputada do PT Martha Suplicy voltou a criticar a frase, dizendo que "as tais moças de 12 anos podem ter corpo e comportamento de moças, mas não são"2.

Assim, de um certo modo, quando se trata de julgar questões que envolvem direitos e infância em nossos tempos, formam-se dois grupos de opiniões. Há, sempre, um grupo que se nutre da idéia da infância como um período prolongado, caracterizado principalmente pela inocência. Contestando este, há o grupo que nutrese da idéia de que a infância, sendo ou não um período longo, pode ser pensada como algo que possui uma série de características, mas nunca a de inocência e bondade como essenciais.

A conversa dos integrantes do primeiro grupo parece afinada com uma herança específica: a que ganhamos com a ruptura proporcionada por Rousseau em relação às concepções de Santo Agostinho e Descartes. Como se sabe, Santo Agostinho viu a criança imersa no pecado, na medida em que, não possuindo a linguagem ("infante": o que não fala, portanto, que não possui logos), mostrar-se-ia desprovida de razão, esta, o reflexo da condição divina em nós, adultos. Descartes viu a idade não-adulta como uma época do cultivo da imaginação, dos sentidos e sensações e da aceitação acrítica das tradições, postas pelos preceptores, tudo o que macularia nosso pensamento, conduzindo-nos mais tarde, uma vez adultos, à dificuldade no uso da razão e, portanto, ao erro. Para os dois, quanto mais cedo saíssemos da condição de crianças, melhor. Rousseau rompeu com isso na medida em que pôs o erro, a mentira e a corrupção como frutos da incapacidade de julgar de quem não pode mais beneficiar-se, para tal, do crivo de um "coração sincero" e puro, próprio da condição infantil, o protótipo da condição do "bom selvagem". A infância, até então a inimiga número um da filosofia, e, portanto, da Verdade e do Bem, agora, invertidamente, seria a própria condição para a filosofia. Nela estariam a inocência e a pureza, necessárias para o acolhimento da verdade e para a participação no que é moralmente correto.

A conversa dos integrantes do segundo grupo, assim me parece, pode ser razoavelmente exemplificada pelo espírito de alguns escritos de Nabokov, francamente fustigadores do rousseauísmo. Podemos, é claro, pensar em Lolita ${ }^{3}$. Mas eu gostaria de atentar, aqui, para o conto Perfeição, no qual o anti-rousseauísmo não aparece mesclado a questões sexuais e, assim, ganha maior amplitude. Trata-se da história de um menino solitário, David, e de seu professor particular, Ivanov. Nabokov procura fazer Ivanov, e nós, leitores, irmos nos afeiçoando, romanticamente, ao garoto. Ivanov, 
até mesmo, dá mostras de atitudes românticas declaradas, quando é incumbido de passar as férias com o menino e, um dia, de volta da praia, o faz reparar na floresta, dizendo rousseauisticamente: "Devemos apreciar os bosques. Foi o primeiro habitat do homem. Um belo dia o homem abandonou a floresta das insinuações primitivas pelo vale ensolarado da razão". Ou seja, no decorrer do conto, Nabokov envolve Ivanov em um clima romântico, ao qual, sabemos, pertence o amor à natureza e o amor à melhor expressão da natureza não maculada pela cultura, a infância a infância inocente. E o conto, então, pode terminar com uma surpresa. Um dia na praia, o garoto finge que está se afogando, e Ivanov, cardíaco - na verdade um pobre-diabo, do qual só não nos apiedamos desde o início porque ficamos demais presos na compaixão pelo garoto solitário -, tenta salvá-lo e morre afogado. O garoto sai sem culpa. Ivanov morre devido a uma brincadeira. Nabokov (1996) espera que tenhamos uma surpresa na medida em que, no final, vemos brotar da cabeça do menino uma atitude, no limite, cruel. Nada mais cruel que uma criança!

Conversas afinadas com um certo espírito nabokoviano podem parecer subversivas em relação à infância clássica, rousseauísta. Mas, de fato, nem sempre fazem muito contra ela. Muitas vezes dão margem, apenas, a um rousseauísmo invertido. Pois seguem a concepção clássica na medida em que podem, muito bem, pensar a infância como um dado natural. A infância não seria inocente, mas nem por isso não cumpriria o destino posto pela sua natureza. Ora, eu penso que há pelo menos duzentos anos, desde Hegel, uma boa parte dos ocidentais começou a conversar sobre as coisas do mundo de modo diferente, considerando-as historicamente construídas. Assim, começa- mos a esboçar uma terceira via para conversarmos sobre as crianças. Novos sentimentos associados a essa nova forma de falar sobre o que fazer com as crianças, em prol da comodidade dos adultos e da comunidade, ganharam algumas pessoas das cidades do Ocidente nos séculos XIX e XX. Nessas conversas, no início do século XIX, a infância já aparece como algo obtido por construçào. Até mesmo uma construção que a entrelaça com a cidade e com a escola. O conto As aventuras de Pinóquio, de Carlo Collodi (1992), é uma narrativa desse tipo.

Como se sabe, o conto começa com um marceneiro, Gepeto, que recebe de presente um pedaço de pau falante e o transforma em um boneco. Pinóquio, o boneco de madeira, não era - é claro - propriamente uma criança. Como nota o Grilo-Falante, o que é pior em Pinóquio é que "ele tem cabeça de pau". Para ser um "menino de verdade" 4 seria preciso ser bom para seu pai e para com os outros, ter responsabilidade, ter sua própria consciência. Assim, a Fada, para o transformar em "menino de verdade", depende de alguns pré-requisitos. Para poder agir sobre a obra da natureza (o pedaço de pau falante) e sobre o trabalho paterno (o boneco de madeira), e transformar Pinóquio em um menino, a Fada necessita que ele já esteja vivendo como tal. Ora, Gepeto sabe muito bem o que deve, então, proporcionar isso a Pinóquio. É a escola. Ao trocar seu próprio casaco por uma cartilha, Gepeto indica que acredita na escola como o local que pode fazer Pinóquio ter condiçôes de viver como um "menino de verdade". Onde fica a escola? Na cidade. A cidade e a escola, então, são responsáveis pela parte mais decisiva da construção da infância. Todavia, elas formam um campo aberto de possibilidades históricas. Nelas, a infância pode ocorrer, más não neces- 
sariamente ocorrerá. Isso fica claro quando Pinóquio vai à cidade, encaminhando-se para a escola, e encontra a Raposa e o Gato, elementos que vivem na cidade, mas que estão longe de ser cidadàos. Desencaminham Pinóquio, mostrando assim as outras possibilidades da cidade. Chegam a mostrar a possibilidade de podermos mudar de cidades, de irmos para cidades terríveis, cidades sem cidadania, como aquela em que habitavam as crianças-as nos, onde Pinóquio quase termina por se transformar completamente em asno.

Como se vê, contrariando Nabokov e Rousseau, o Pinóquio de Collodi não é essencialmente mau nem bom, é apenas um boneco de pau. Contrariando outros autores, a cidade de Collodi não está sujeita a, digamos, leis histórico-naturais - nela tudo pode acontecer. Se Pinóquio for bom e responsável terá feito desta época de sua vida um trampolim para poder dizer, "sou um menino de verdade". Ao final do conto ele, de fato, transforma-se em menino de verdade, na medida em que, contrariando aqueles que não são cidadãos e que gostariam de fazer dele também um não-cidadão, o Gato e a Raposa e outros personagens do mesmo tipo, ele desenvolve comportamentos que indicam, aos olhos de seu pai e da Fada, responsabilidade e bondade.

Nós, ocidentais, desde o final do século XVIII, e mais decisivamente no século XIX, ao mesmo tempo que começamos a descrever a infância como algo natural, segundo um recorte que se pretendia único, também utilizamos, paradoxalmente, outras descriçōes, como a contida em Pinóquio. Nesta, a infância é algo recortado de modo menos rígido, dependente menos de leis naturais e mais de construção histórica. Por este segundo tipo de descriçào, vimos a infância como algo para cuja constituição concorrem várias forças culturais e completamente contingentes, entre as quais, a cidade e a escola se tornaram muito importantes.

Mas o historicismo ensaiado no conto de Collodi é bastante ameno perto do que fizemos, mais recentemente, principalmente nos últimos quarenta anos. Mais do que conversarmos sobre a infância de cada criança como algo que não é de todo natural, passamos a falar sobre a própria idéia de "infância natural" como algo historicamente criado! $\mathrm{E}$ os que seguiram este caminho, como Philippe Ariès no início dos anos 60 , ensinaram uma maneira de conversar sobre a infância bastante distante das formas utilizadas pelos dois grupos inicialmente aludidos, os inspirados na virada rousseauísta e os representados pelo espírito nabokoviano. Philippe Ariès deu continuidade à terceira via, a de Hegel e Collodi.

É certo que Ariès (1981) fala em "descoberta da infância" e, com isso, nubla um pouco a idéia de invenção da infância. Assim, com Ariès, ainda poderíamos pensar na infância como uma fase natural dos seres humanos, nunca antes percebida, mas que em certo momento é encontrada por intelectuais de melhor visão. Tratar-se-ia, então, de fazer cada criança viver sob condições específicas, para que sua infância pudesse ocorrer da maneira como a natureza programou. Mas não é este o espírito do texto de Ariès. Ele trata a noçào de infância como algo que vai sendo montado, criado a partir das novas formas de falar e sentir dos adultos em relação ao que fazer com as crianças. Em Pinóquio, a escola e a cidade são elementos que concorrem para que o boneco se torne um "menino de verdade". Ou seja, são as forças culturais, completamente contingentes, que estão presentes e que forjam a infância. Em Ariès, de modo mais abrangente e radical, as próprias noções que diferenciam 
um menino de um adulto aparecem como criação - criação prática a partir da conversação e dos afetos que os grupos urbanos desenvolvem a respeito de seus filhos. Levar o historicismo de Ariès adiante é, então, admitir que não somente a idéia de infância clássica é uma invenção, mas, claro, que o mesmo pode ser dito da sua inversão nabokoviana. E mais, que quaisquer descrições da infância, sejam elas postas pela ciência, pela filosofia, pela literatura e pelas artes em geral, são, enfim, apenas novas descrições. Elas não permitem que as mensuremos nos referindo a uma superdescrição que seria, então, a "verdade sobre o que é o menino de verdade".

$\mathrm{O}$ que significa conversar sobre as crianças desse modo? Significa não acreditar que os "direitos da infância" todos esses direitos de proteção já conquistados, e aqueles a conquistar e a inventar, na cultura liberal-democrática do Ocidente - podem ser ditos válidos porque assentados na verdade teórica que nos pretende dizer "o que é a infância”. Significa não mais procurar explicar e justificar os direitos da criança a partir da "verdadeira definição de menino de verdade". Mas, então, os direitos da infância estão condenados? Nem sim, nem não. Como assim? Talvez Gepeto possa nos ensinar algo sobre isso.

Gepeto não sabia muito bem o que era ser um "menino de verdade", a não ser o que todos os habitantes razoáveis da cidade sempre disseram, que um menino devia ser bom e responsável, ter uma consciência e não uma "cabeça de pau". O que ele sabia muito bem é que a cidade oferecia um espaço próprio para todos os meninos. Na escola, entendia Gepeto, viver-se-ia como "menino de verdade" para, enfim, tornar-se "menino de verdade". Gepeto não esperava encontrar na entrada da escola um aviso do tipo "Aqui não acei- tamos bonecos de pau, só meninos de verdade", e, de fato, não encontrou. Por um acordo histórico e cultural a cidade em que vivia Gepeto reservou para as crianças um espaço, isto é, mais um direito da infância, pouco se importando, para tal, em perguntar aos seus sábios locais ou estrangeiros o que era, verdadeira e objetivamente, um "menino de verdade".

Mas não só fundamentar os direitos da infância na verdade teórica sobre a infância é pouco possível para uma cultura historicista, da qual participam muitos em nossos tempos. Para alguns que participam dessa cultura, isso pode mesmo, até, ser um perigo. Circunscrever os "direitos da criança" a partir de uma rígida delimitação da infância segundo uma única descrição significa, também, abrir caminho para que muitos bonecos de pau não usufruam desses direitos. Se cairmos na tentação - de padres, metafísicos e cientistas - de fundamentar os direitos das crianças a partir da "verdade sobre o que é o menino de verdade", talvez a maior parte das crianças fique de fora das nossas conversas e, pior, dos nossos cuidados e preocupações. Um exemplo?

Sim, vou dar um exemplo. O relato de Andrew Sullivan (1996) é apropriado para o que quero dizer aqui. Reproduzo, então, dois trechos do seu curioso livro, o Praticamente normal - uma discussão sobre o homossexualismo.

1. "Lembro-me de que aos sete ou oito anos vi certa noite na televisão um homem de peito nu e senti um anseio tão intenso por ele que decidi tornarme médico. Assim, pensei eu, poderia fazer o homem ficar inconsciente $e$ deitar em cima dele quando não houvesse mais ninguém na sala. Mas aí, percebi depressa, eu seria descoberto $e$ me meteria numa encrenca. Passei a maior parte da noite acordado imaginando essa cena, e acabei tão confuso 
e tào dominado pelo desejo como no início" (Sullivan, 1996, p.14-5).

2. "Lembro-me especificamente de um reinício das aulas depois de um longo verão, quando eu tinha quinze anos. Pela primeira vez eu voltava a trocar de roupa no vestiário junto com um rapaz por quem vinha tendo uma prolongada paixonite. Porém, desde as férias ele se desenvolvera enormemente: de repente estava cheio de pêlos no peito, seu corpo crescera e se fortalecera; nào era mais um menino. Ele tirou a camisa diante de mim e inconsciente, lenta e eroticamente fez um strip-tease. Fiquei literalmente sem fôlego, tomado pela proximidade do meu desejo. Em momentos como esse, o adolescente gay aprende um tipo de controle e sublimação, de enganação e autodesprezo, que nunca deixará sua consciência" (Sullivan, 1996, p.18).

Ora, aonde quero chegar apontando esses dois trechos do livro de Sullivan? Quero discutir as reaçôes que podem se apoderar de nós na leitura de tais trechos. Didaticamente, descrevo-as em dois tipos.

Se a infância inocente é a verdade sobre a infância, e se tomamos o desejo erótico como o que macula a inocência, então a criança gay aqui apresentada, para nós, não é criança, pois argumentaríamos que ela não poderia sustentar sua inocência. Ela nào poderia usufruir de direitos da infância, na medida em que a decretamos um estranho no mundo infantil. E pouca coisa muda se tomamos o desejo erótico como "normal", "natural". Pois podemos pensar que os pais de Sullivan devem e podem se sentir felizes com um filho como o menino Sullivan - um menino normal -, sem que isso signifique que somos capazes de admitir que os nossos filhos também são assim, ou, ainda, que nós fomos assim como Sullivan. Isto é, deste modo, o menino Sullivan usufrui- 
ria dos "direitos da infância" por um ato de piedade, por uma condescendência nossa, mas não porque o estivéssemos considerando "um de nós".

Mas talvez tomemos decisòes por outros motivos. É possivel que passemos a tomar atitudes mais amplas em relação à fruição de direitos da infância após nós mesmos redescrevermos nossa infầncia, atingidos pelo que Sullivan relatou. Podemos recordar que, quando crianças, também tivemos experiências eróticas hetero e/ou homossexuais, com desejos tão intensos quanto os de Sullivan, e, em tal época, não nos sentíamos não sendo crianças. Ou, pelo menos, não nos sentíamos não merecedores de vivermos "como meninos" ou "como meninas" quando se tratava de brincar, de comer doce e tomar sorvete, de jogar bola ou de ler gibi. Todavia, podemos também lembrar ou imaginar que alguns de nós, ao serem flagrados com desejos e práticas como as de Sullivan, não mais foram descritos como crianças, e a estes, a partir daí, foi negada a infância. Não foram mais vistos como "meninos e meninas de verdade" e, então, se viram proibidos de continuar suas vidas de crianças. Para tais crianças, muitas vezes, a escola da cidade não cumpre o que Gepeto dela esperava: que ela acolha todas as crianças.

Na primeira reação, o historicismo de Ariès não teve lugar. Ficamos no velho essencialismo. Com a segunda reação nos aproximamos de uma posição pós-moderna e concomitantemente democrática, e levamos o historicismo de Ariès para dar mais um passo. Aprofundamos nossa cultura historicista, sem com isso negar apreço pela democracia, pelo contrário, penso que, de certo modo, colaboramos com ela.

Redescrever nossa infância e, assim, considerar o menino Sullivan como "um de nós" nos mostra assentando nossa solidariedade na possibilidade da compaixão criada a partir da memória e da imaginação, e não a partir da theoria, e muito menos a partir da piedade. Significa, em relação à infância, viver no mundo pós-moderno descrito por Lyotard - no qual abandonamos as metanarrativas - sem abrir mão dos ganhos democráticos da civilização ocidental moderna, como os "direitos da infância". Penso que Richard Rorty veria esta atitude, diante da infância, como algo próprio do comportamento de um "liberal ironista", pelo qual ele revela apreço. Gepeto era alguém que caminhava para isso! Penso então que faríamos melhor fazendo como Gepeto: se a escola e a cidade são aqueles lugares onde meus amigos razoáveis dizem que devemos pôr as crianças, e se eu tenho uma criança aqui, o meu Pinóquio, então eu vou procurar a cidade e nela a escola. Pode ser que eu não encontre a cidade. Pode ser que nela não exista escola. Pode ser que eu encontre alguém que queira insinuar que meu Pinóquio é só um boneco. Tudo isso pode ocorrer. Mas o conselho dos amigos razoáveis de Gepeto era a única coisa na qual ele podia confiar - era seu único... fundamento! E ele os seguiu. $O$ que mais ele podia fazer? 


\section{REFERÊNCIAS BIBLIOGRÁFICAS}

Ariès, P. (1981). História social da criança e da familia (D. Flaksman, trad.). Rio de Janeiro, RJ: Guanabara.

Collodi, C. (1992). As aventuras de Pinóquio. São Paulo, SP: Paulinas.

Nabokov, V. (1994). Lolita (J. Dauster, trad.). São Paulo, SP: Companhia das Letras.

das Letras.

Rorty, R. (1989). Contingency, irony and solidarity. Cambridge: Cambridge University Press.

. (1994). Contingência, ironia e solidariedade (N. F. da Costa, trad.). Lisboa: Presença.

Sullivan, A. (1996). Praticamente normal (I. M. Lando, trad.). São Paulo, SP: Companhia das Letras.

\section{NOTAS}

${ }^{1}$ Este texto teve origem em uma participação no evento "Cidades educadoras contra a exclusão e pela paz", organizado pela Universidade Federal do Paraná, pela Unesco, pelo Collège des Hautes Études Européennes Miguel Servet e pela Associação de Universidades Grupo Montevideo do Mercosul, em Curitiba, entre $1^{\circ}$ e 4 de setembro de 1996. Uma versào preliminar foi publicada pela Universidade Federal do Paraná.

Para Martha Christina Martins e Heloisa Fernandes, que amorosa e inteligentemente discutiram o texto comigo, para Richard Rorty, Bjorn Ramberg, Renato Janine Ribeiro e Jurandir Freire Costa, que são minhas queridas fontes inspiradoras.

\section{Folha de S.Paulo, 27/7/96, Caderno 3, p.2.}

3 Em Lolita, Nabokov põe a concepçào rousseauísta da infância em papos-dearanha, também explicitamente. Ver para tal o saboroso Capítulo 28, no qual o personagem Humbert, ao se preparar para se deleitar com o corpo de Lolita, entào com 12 anos, consola-se lembrando que ela estará dormindo (está dopada) e que ele, no limite, não irá completar o ato. O consolo é para com sua consciência de, como diz, "habitante do Velho Mundo", "eu, Jean-Jacques Humbert". Cf. Nabokov, 1994.

4 Collodi não usa a expressão "menino de verdade", e sim a expressão "um menino como os outros". A expressào "menino de verdade" é utilizada, se não me falha a memória da infância, na versão Disney para o cinema (refiro-me à dublagem em português, é claro). 